\title{
Effect of electron beam irradiation on the mechanical properties of buriti fiber
}

Barbosa, A. P. ' , Costa, L L. ${ }^{1}$,

Portela, T. G. R. ${ }^{1}$, Moura, E. A. ${ }^{2}$, Del Mastro, N. L. ${ }^{2}$, Satyanarayana, K. G. ${ }^{3}$, Monteiro, S. N. ${ }^{4}$

\author{
${ }^{1}$ State University of the Northern Rio de Janeiro, UENF, \\ e-mail: apbarbosa12@yahoo.com.br; luclopes@hotmail.com; tammygodinho@gmail.com \\ ${ }^{2}$ IPEN, São Paulo, SP, Brazil \\ e-mail: eabmoura@ipen.br; nlmastro@ipen.br \\ ${ }^{3}$ Acharya Research \& Development Center, Soladevanhalli, Bangalore, India \\ e-mail:.kgs_satya@yahoo.co.in \\ ${ }^{4}$ IME: Military Institute of Engineering, Department of Materials Science, Praça General Tibúrcio, 80, \\ 22290-270, Rio de Janeiro, Brazil. \\ e-mail: sergio.neves@ig.com.br
}

\section{ABSTRACT}

Natural fibers, mainly those lignocellulosic extracted from plants, have, in the past few decades, attracted the attention not only of scientists but also of industrial technologists of our society interested in their engineering materials. As it is well known, uses of natural fiber in clothes carpets, baskets, ropes and low cost construction roofing has existed from the beginning of our civilization. Today environmental and energy saving issues are motivating research works on new uses of lignocellulosic fibers in polymer composites. Moreover, industrial application of lignocellulosic fiber composites are already in technological sectors such the automobile industry, packing and civil construction. In addition to environmental, economical and social benefits, some lignocellulosic fibers present specific properties that are not comparable to those of other synthetic fiber used for polymer composite reinforcement. In fact, the mechanical strength and stiffness of any natural fibers is, however, significantly inferior and needs to be improved in order to compete with those of the synthetic fibers. The present work investigated the effect of electron beam irradiation on the mechanical behavior of the buriti petiole fiber, which presents a potential for composite reinforcement. Distinct lots of buriti fibers were irradiated at 50, 250 and $500 \mathrm{kGy}$ using a $1.5 \mathrm{MeV}$ electron beam accelerator. The results showed marked changes in the tensile properties of the buriti petiole fiber. This was discussed in terms of the structural modifications occurring in the irradiated lignocellulosic structure.

Keywords: Buriti fibers, electron beam irradiation, mechanical properties. 


\section{INTRODUCTION}

The use of materials extracted from plants can be traced back to thousands of years [1]. It is documented that wood and other lignocellulosic materials have been used from the beginning of our civilization. In particular, there are evidences that lignocellulosic fibers were, since then, applied in simple items such as ropes, baskets, roofing and even as reinforcement of sun-dried clayey adobe in earlier building construction. In the past century, however, synthetic fibers fabricated from polymers, glass and carbon continuously replaced the natural fibers in their traditional applications. Moreover, the synthetic fibers were preferentially considered for composite reinforcement [2-4] owing to their superior strength and stiffness.

Today, a reverse trend in favor of lignocellulosic fibers is taking place as a consequence of environmental problems related to the synthetic fibers. In fact, synthetic fibers require a relatively large amount of energy for their production and processing. This corresponds to a surplus of $\mathrm{CO}_{2}$ emission, which is the main responsible for global warming. Synthetic fibers and their composites cannot also be recycled and cause long term pollution after discard. Thus, a considerable number of works has in recent years been dedicated to the investigation and possible applications of composites alternatively reinforced with lignocellulosic fibers [5-10]. In addition to environmental benefits, lignocellulosic fibers also present economical societal and some technical advantages $[9,10]$. By contrast, they also possess drawbacks in terms of low adhesion to polymer matrices as well as non-uniform properties. In spite of these limitations, efforts are being made to improve the mechanical performance not only of the lignocellulosic fibers but also their reinforced composites [11]. A possible way to increase the strength of a lignocellulosic fiber or its polymeric composite is by subject them to radiation $[12, \underline{13]}$.

It is well known that radiation may significantly affect molecular materials even for relatively small doses [12]. Inter and intra-molecular reactions may promote crosslink and reticulate network in a macromolecular structure, either natural or synthetic, which has been irradiated. For instance, ionizing irradiation of a polymeric material is able to break chemical bonds and introduce modification in the material behavior [12-14]. Several works [15-20] have shown that macromolecular products such as natural fibers, biomaterials and polymers may improve their properties by ionizing irradiation as a result of crosslinking and scission processes, in which radicals are formed throughout the chains.

The fiber extracted from the petiole of the buriti palm tree has recently been investigated as a promising reinforcement for polymer composites [21-23]. However, the strength of this fiber, of the order of $200 \mathrm{MPa}$, is lower than other lignocellulosic fibers, such as curaua, ramie and sisal [11]. It was then investigated in the present work, the possibility of improving the strength of buriti petiole fibers by electron beam irradiation.

\section{EXPERIMENTAL PROCEDURE}

The buriti fibers used in this work were extracted from petioles of the palm tree, Figure 1, supplied by Nubia S.S. Santos from the state of Para, North o Brazil. Fibers also shown in Figure 1 were longitudinally cut from the petiole. Three different lots of fibers were considered for distinct electron beam irradiation doses. Initially, 100 fibers, randomly taken from each lot, were statistically evaluated in terms of the equivalent diameter measured by profile projector, as described elsewhere [22]. 

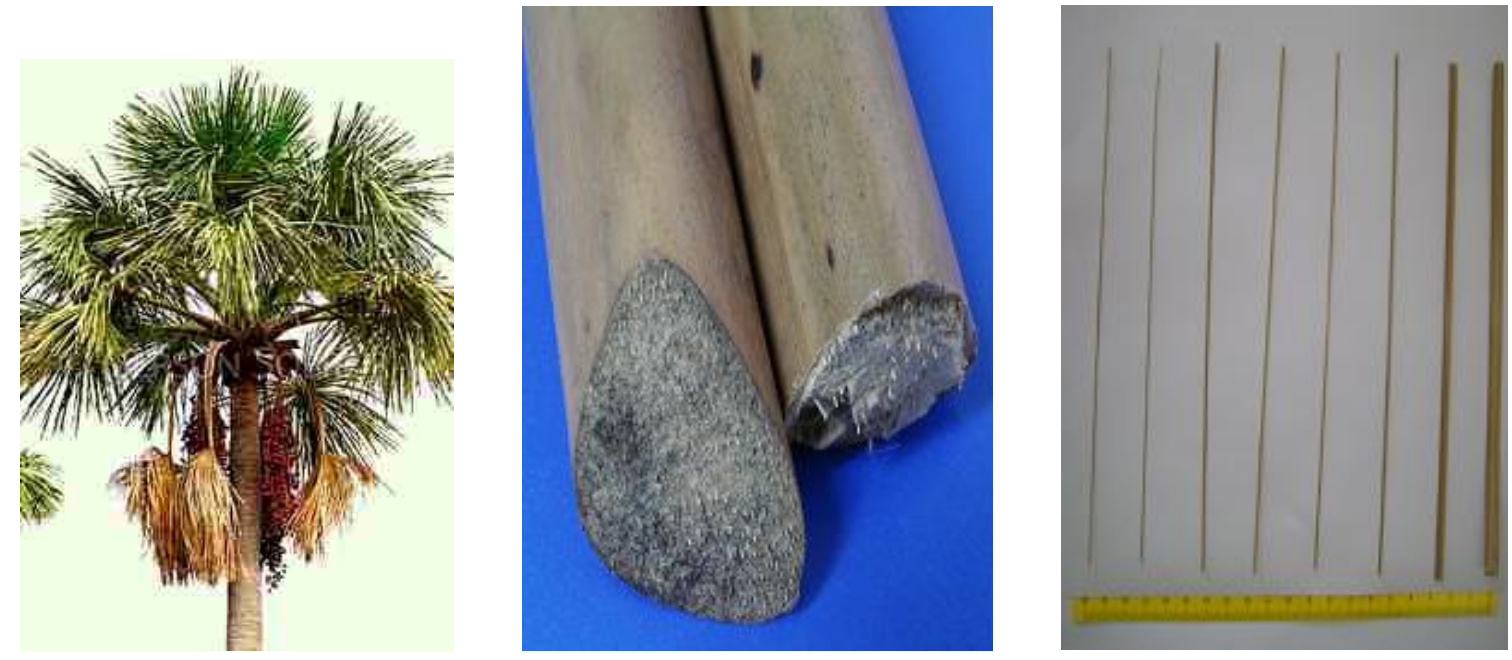

Figure 1: The buriti palm tree (a), petioles (b) and extracted fibers (c).

Figure 2 shows the histograms corresponding to the statistical distribution of diameters for each lot of buriti fiber before irradiation. In this figure one should notice that each lot was conventionally divided in 6 intervals of diameter from 0.42 to $1.02 \mathrm{~mm}$. Although the actual distribution varies for every corresponding interval in each lot, the mean diameter per lot is approximately the same, $\mathrm{dm}=0.7 \mathrm{~mm}$ and similar to another value of $\mathrm{dm}=0.6 \mathrm{~mm}$ found elsewhere [22].

Buriti fibers from the three different lots were cleaned and dried before electron beam irradiation. Irradiation was conducted in a model Dynamitron II Radiation Dynamics electrostatic accelerator operating at $25^{\circ} \mathrm{C}$, in the presence of air, with a beam width of $100 \mathrm{~cm}$. The dose rate was $22.42 \mathrm{kGy} / \mathrm{s}$ associated with an energy of $1.487 \mathrm{MeV}$, a beam current of $5.59 \mathrm{~mA}$ and a tray speed of $6.72 \mathrm{~m} / \mathrm{min}$. The total applied dose for fibers of lot A was $50 \mathrm{kGy}$; lot B was $250 \mathrm{kGy}$, and lot C $500 \mathrm{kGy}$. The dose measurements were carried out with cellulose triacetate film dosimeters model CTA FTR 125 Fuji Photo Film. After irradiation, the buriti fibers were stored inside plastic bags in a dried and protected ambient until being tested.
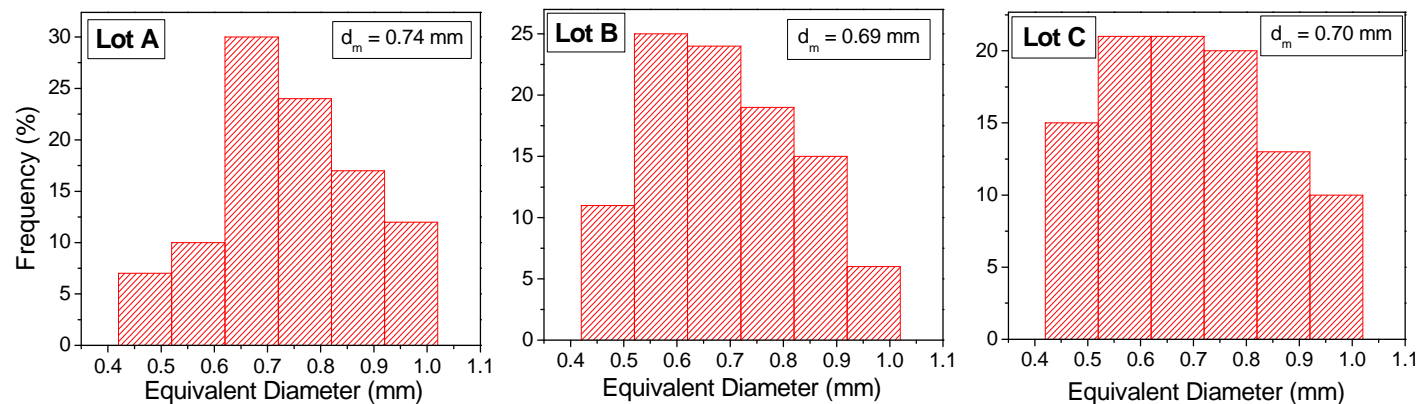

Figure 2: Histograms of diameter distribution for lots A, B, and C of buriti petiole fibers.

Tensile tests were performed in a model 5567 Instron machine with pneumatic grips operating with a holding pressure of 0.6 MPa, which prevents slippage without damaging the fiber. The test temperature was an acclimatized $25^{\circ} \mathrm{C}$ and a strain rate of $6.7 \times 10-4 \mathrm{~s}-1$. Tensile ruptured fibers were attached to a metallic support and coated with platinum to be analyzed by scanning electron microscopy, SEM, in a model SSX550 Shimadzu microscope operating with secondary electrons accelerated at $15 \mathrm{kV}$. 


\section{RESULTS AND DISCUSSION}

For each diameter interval presented in Figure 2, ten fibers were tensile tested and the ultimate strength, $\sigma \mathrm{m}$, of every fiber was calculated by the maximum force, Fm, divided by the fiber cross-section area with average equivalent diameter, de, as shown in the following equation.

$$
\sigma \mathrm{m}=4 \mathrm{Fm} / \pi \mathrm{de}
$$

The results of the tensile strength of each fiber belonging to the diameter intervals, Figure 2, for the three lots of buriti fibers electron beam irradiated with different doses, were statistically analyzed using the Weibull method. This method permits to construct graphs such as the ones in Figure 3 for set of points corresponding to each diameter interval.
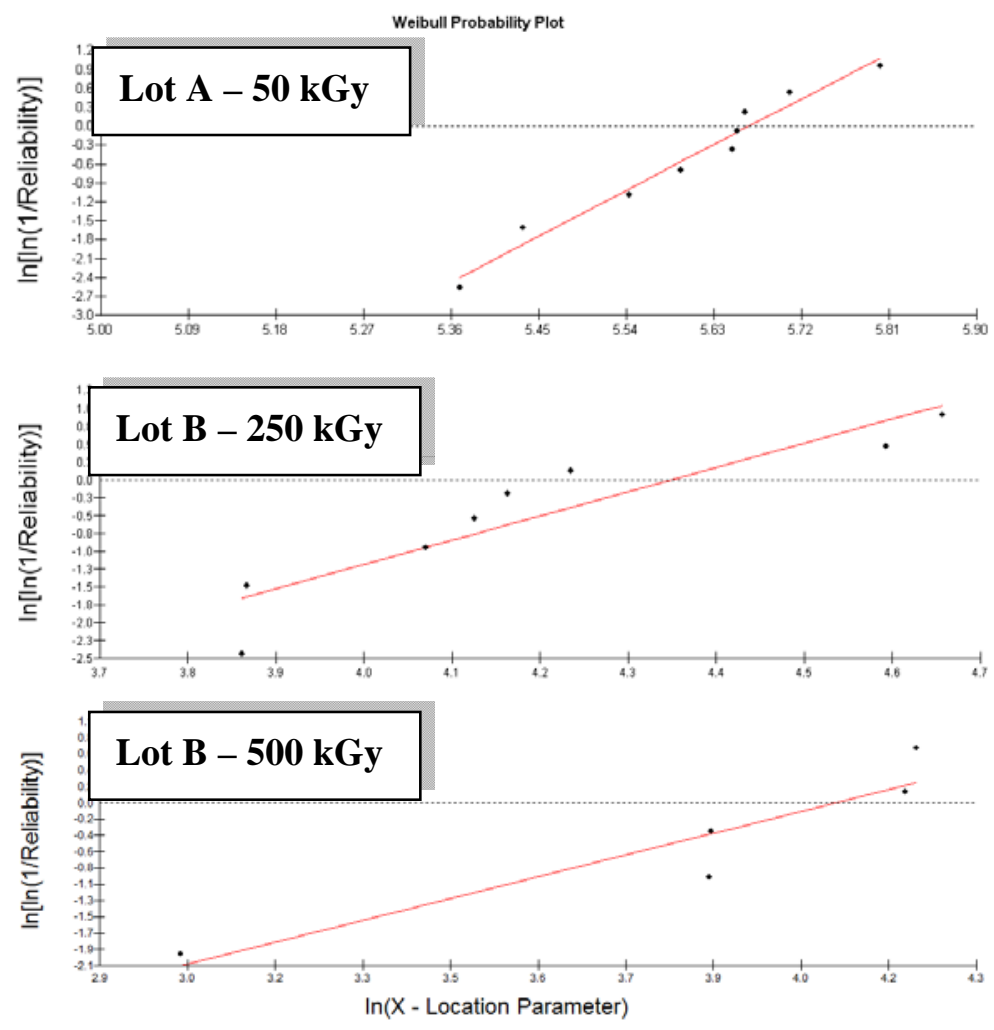

Figure 3: Examples of Weibull graphs for the intervals of thinner diameters $(0.42<\mathrm{de}<0.52)$ for the three lots irradiated with different doses.

In this figure, as illustrative examples, only the graphs for the interval of thinner diameters, from 0.42 to $0.52 \mathrm{~mm}$ are presented. Here it is important to mention that all Weibull graphs, like the ones in Figure 3 , are unimodal, i.e., with just one fitting straight line. This is an indicative that fibers associated with a given diameter interval have the same mechanical behavior.

The Weibull Analysis program also provides the values of corresponding parameters for each diameter interval: characteristic stress $(\theta)$, Weibull modulus $(\beta)$, and the precision adjustment (R2). Tables 1 to 3 present for irradiation doses of 50, 250 and $500 \mathrm{kGy}$, respectively, these Weibull parameters as well as the mean tensile strength and corresponding deviation for each diameter interval. It should be noted in these tables the relatively good values of $\mathrm{R} 2$, indicating a reasonable adjustment of the results. 
Table 1: Weibull parameters for the tensile strength of buriti fibers associated with different diameter intervals and electron beam irradiated with $50 \mathrm{kGy}$

\begin{tabular}{c|c|c|c|c|c}
\hline $\begin{array}{c}\text { DIAMATER } \\
\text { INTERVAL } \\
(\mathbf{m m})\end{array}$ & $\begin{array}{c}\boldsymbol{\theta} \\
\mathbf{( M P a )}\end{array}$ & $\boldsymbol{\beta}$ & $\mathbf{R}^{\mathbf{2}}$ & $\begin{array}{c}\text { MEAN TENSILE } \\
\text { STRENGTH } \\
\mathbf{( M P a )}\end{array}$ & $\begin{array}{c}\text { STATISTICAL } \\
\text { DEVIATION } \\
\mathbf{( M P a )}\end{array}$ \\
\hline $\mathbf{0 . 4 2}-\mathbf{0 . 5 2}$ & 288.9 & 8.066 & 0.9703 & 272.2 & 40.07 \\
\hline $\mathbf{0 . 5 2}-\mathbf{0 . 6 2}$ & 281.3 & 3.273 & 0.9575 & 252.2 & 84.78 \\
\hline $\mathbf{0 . 6 2}-\mathbf{0 . 7 2}$ & 260.4 & 3.091 & 0.9307 & 232.8 & 82.39 \\
\hline $\mathbf{0 . 7 2}-\mathbf{0 . 8 2}$ & 254.3 & 5.224 & 0.9514 & 234.1 & 51.51 \\
\hline $\mathbf{0 . 8 2}-\mathbf{0 . 9 2}$ & 243.9 & 4.915 & 0.8604 & 223.7 & 52.05 \\
\hline $\mathbf{0 . 9 2}-\mathbf{1 . 0 2}$ & 187.4 & 5.712 & 0.9871 & 173.4 & 35.15 \\
\hline
\end{tabular}

Table 2: Weibull parameters for the tensile strength of buriti fibers associated with different diameter intervals and electron beam irradiated with $250 \mathrm{kGy}$

\begin{tabular}{c|c|c|c|c|c}
\hline $\begin{array}{c}\text { DIAMATER } \\
\text { INTERVAL } \\
(\mathbf{m m})\end{array}$ & $\begin{array}{c}\boldsymbol{\theta} \\
\mathbf{( M P a )}\end{array}$ & $\boldsymbol{\beta}$ & $\mathbf{R}^{\mathbf{2}}$ & $\begin{array}{c}\text { MEAN TENSILE } \\
\text { STRENGTH } \\
\mathbf{( M P a )}\end{array}$ & $\begin{array}{c}\text { STATISTICAL } \\
\text { DEVIATION } \\
\mathbf{( M P a )}\end{array}$ \\
\hline $\mathbf{0 . 4 2}-\mathbf{0 . 5 2}$ & 77.34 & 3.393 & 0.8459 & 69.47 & 22.61 \\
\hline $\mathbf{0 . 5 2}-\mathbf{0 . 6 2}$ & 80.61 & 2.427 & 0.8529 & 71,47 & 31.41 \\
\hline $\mathbf{0 . 6 2}-\mathbf{0 . 7 2}$ & 92.66 & 2.815 & 0.8024 & 82.53 & 31.75 \\
\hline $\mathbf{0 . 7 2}-\mathbf{0 . 8 2}$ & 76.56 & 2.147 & 0,9593 & 67.8 & 33.25 \\
\hline $\mathbf{0 . 8 2}-\mathbf{0 . 9 2}$ & 78.34 & 2.488 & 0.92 & 69.5 & 29.87 \\
\hline $\mathbf{0 . 9 2}-\mathbf{1 . 0 2}$ & 82.12 & 2.257 & 0.8871 & 72.74 & 34.11 \\
\hline
\end{tabular}

Table 3: Weibull parameters for the tensile strength of buriti fibers associated with different diameter intervals and electron beam irradiated with $500 \mathrm{kGy}$

\begin{tabular}{c|c|c|c|c|c}
\hline $\begin{array}{c}\text { DIAMATER } \\
\text { INTERVAL } \\
(\mathbf{m m})\end{array}$ & $\begin{array}{c}\boldsymbol{\theta} \\
\mathbf{( M P a )}\end{array}$ & $\boldsymbol{\beta}$ & $\mathbf{R}^{\mathbf{2}}$ & $\begin{array}{c}\text { MEAN TENSILE } \\
\text { STRENGTH } \\
\mathbf{( M P a )}\end{array}$ & $\begin{array}{c}\text { STATISTICAL } \\
\text { DEVIATION } \\
\mathbf{( M P a )}\end{array}$ \\
\hline $\mathbf{0 . 4 2}-\mathbf{0 . 5 2}$ & 58.93 & 2.028 & 0.872 & 52.21 & 26.95 \\
\hline $\mathbf{0 . 5 2}-\mathbf{0 . 6 2}$ & 39.69 & 2.86 & 0.9096 & 35.37 & 13.42 \\
\hline $\mathbf{0 . 6 2}-\mathbf{0 . 7 2}$ & 45.68 & 3.579 & 0.8318 & 41.45 & 12.76 \\
\hline $\mathbf{0 . 7 2}-\mathbf{0 . 8 2}$ & 35.44 & 2.248 & 0.8704 & 31.39 & 14.77 \\
\hline $\mathbf{0 . 8 2}-\mathbf{0 . 9 2}$ & 43.95 & 2.545 & 0.9584 & 39.01 & 16.43 \\
\hline $\mathbf{0 . 9 2}-\mathbf{1 . 0 2}$ & 25.2 & 1.455 & 0.9883 & 22.84 & 15.95 \\
\hline
\end{tabular}

Figure 4 to 6 depict both, the characteristic stress and the tensile strength, as a function of the buriti fiber diameter, respectively for electron beam irradiation doses of 50, 250 and $500 \mathrm{kGy}$. In these figures, relevant points are to be noticed. First, for the small radiation dose of $50 \mathrm{kGy}$, Figure 4, there is a clear tendency of $\theta$ and the tensile strength $\sigma \mathrm{m}$, to decrease with increasing diameter. This is similar to results obtained in other lignocellulosic fibers [11] as well as in non-irradiated buriti petiole fibers [22]. 

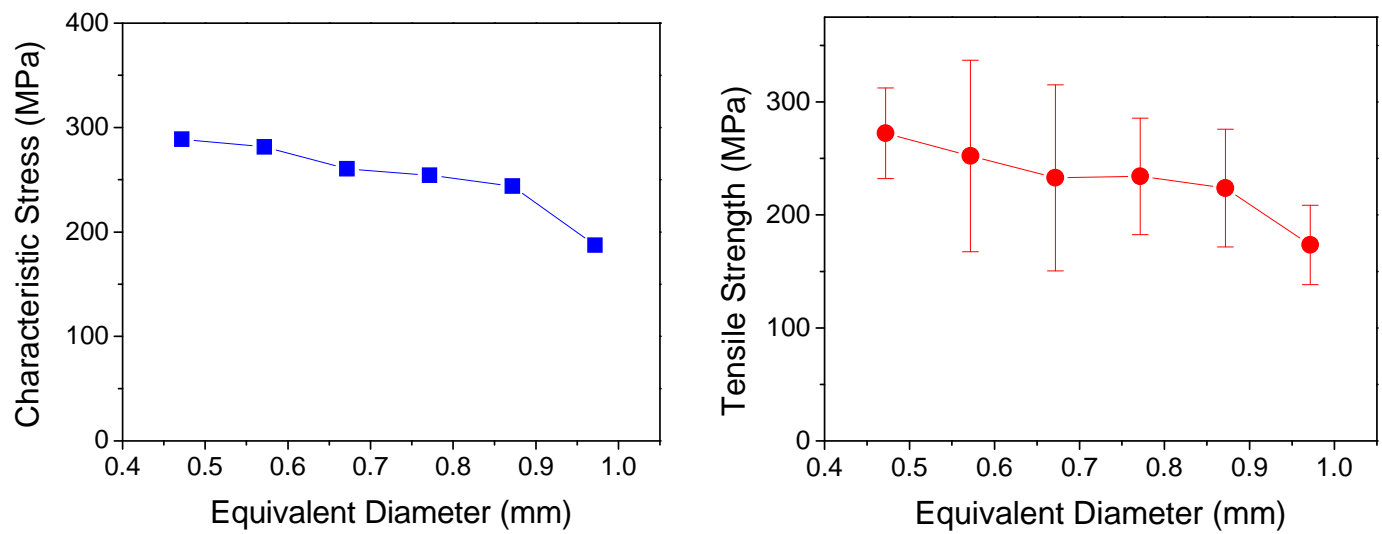

Figura 4: Variation of the characteristic stress and the tensile strength with the diameter of buriti fibers electron beam irradiated with $50 \mathrm{kGy}$
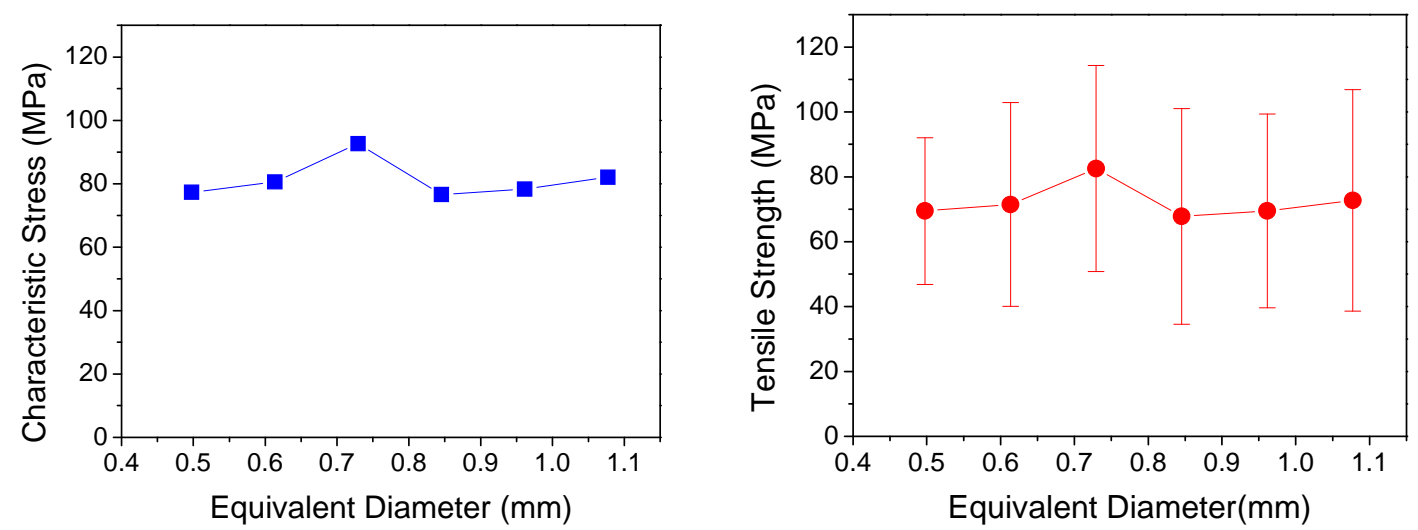

Figura 5: Variation of the characteristic stress and the tensile strength with the diameter of buriti fibers electron beam irradiated with $250 \mathrm{kGy}$.
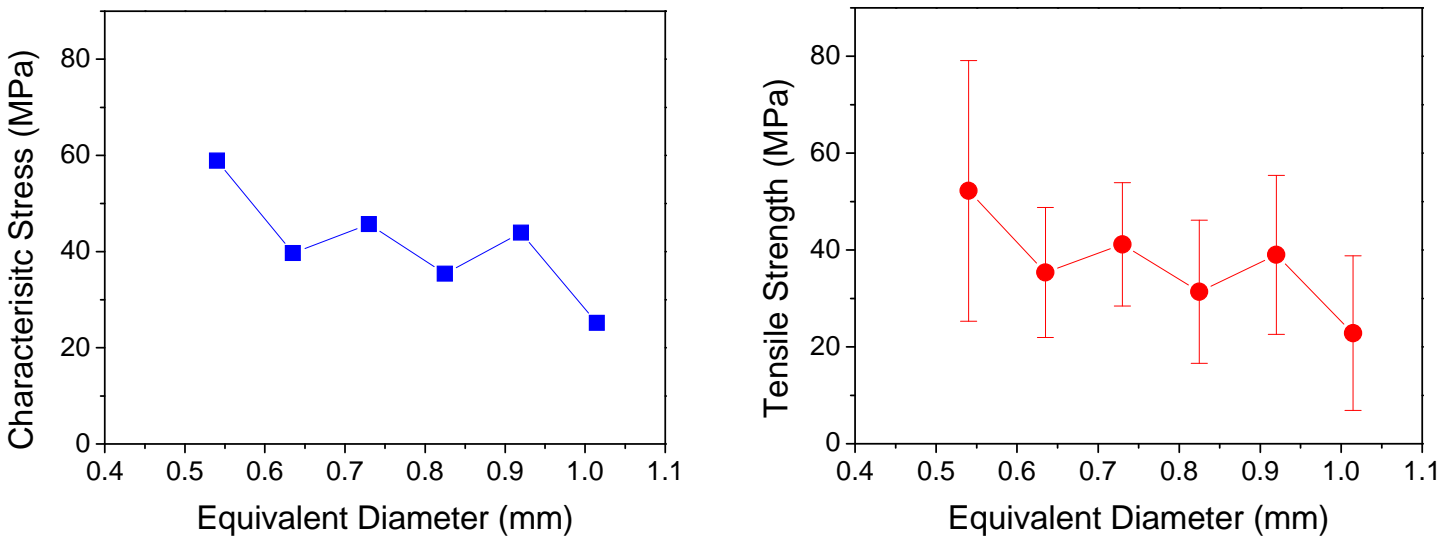

Figura 6: Variation of the characteristic stress and the tensile strength with the diameter of buriti fibers electron beam irradiated with $500 \mathrm{kGy}$. 
Secondly, in average, the values of $\theta$ and om shown in Figure 4 are almost $30 \%$ greater than those for the non-irradiated fibers [22]. This clearly indicates that the $50 \mathrm{kGy}$ electron beam irradiation improves the buriti fiber strength. By contrast, for the higher irradiation doses of $250 \mathrm{kGy}$ in Figure 5 and $500 \mathrm{kGy}$ in Figure 6 , there is a significant decrease in $\theta$ and $\sigma \mathrm{m}$. In other words, relatively higher doses can markedly impair the tensile strength of the buriti fiber. The reason for this behavior can be understood in terms of microstructure effects caused by the irradiation.

Figure 7 presents, with the same magnification of 50X, typical SEM micrographs of tensile ruptured buriti fibers irradiated with different doses. In this figure, it is observed that the fracture of fibers subjected to the lower dose of $50 \mathrm{kGy}$, Figure 7(a), has a significant participation of fibrils and evidence of plastic fracture. In fact, the sequential rupture of fibrils is able to support an increasing applied force to a lignocellulosic fiber [9]. For greater doses corresponding to $250 \mathrm{kGy}$, Figure 7(b), and $500 \mathrm{kGy}$, Figure 7(c), however, the participation of individual fibrils is no longer observed. A buriti fiber subjected to these higher doses presents not only a totally brittle fracture, but also evidence of damages associated with surface degradation in terms of cavities and warped structures.
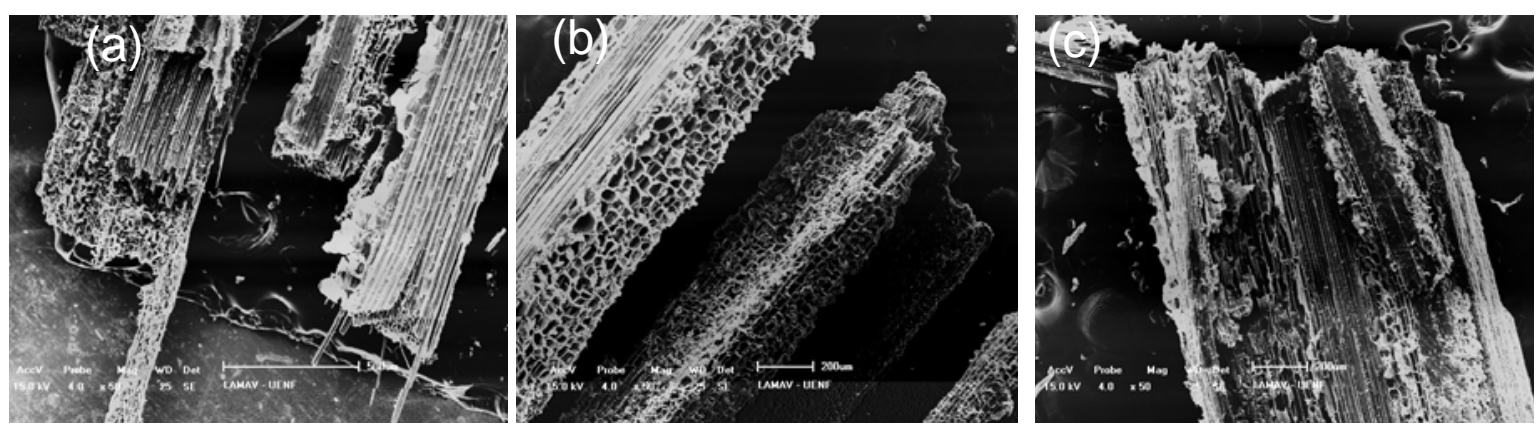

Figure 7: SEM micrographs of tensile ruptured buriti fibers subjected to electron beam irradiation doses of (a) 50, (b) 250 and (c) $500 \mathrm{kGy}(50 \mathrm{X})$.

\section{CONCLUSIONS}

Electron beam irradiation of fibers extracted from the petiole of buriti palm tree caused significant changes in the tensile strength as revealed by Weibull statistical analysis.

For the lower doses of $50 \mathrm{kGy}$, in average, the buriti fibers became almost $30 \%$ stronger than similar non-irradiated fibers. Moreover, there is evidence of an inverse relationship between the strength and the diameter such as that the thinner the diameter, the stronger the fiber.

For higher doses, 250 and $500 \mathrm{kGy}$, the fiber strength was markedly decreased, which could be attributed to structural damages in association with brittle fracture.

\section{ACKNOWLEDGEMENTS}

The authors thank the support to this investigation by the Brazilian agencies CNPq, CAPES, FINEP and FAPERJ.

\section{REFERENCES}

[1] SATYANARAYANA, K.G., GUIMARÃES, J.L., WYPYCH, F., "Studies on lignocellulosic fibers of Brazil. Part I: Source, production, morphology, properties and applications”, Composites: Part A, vol. 38, pp.1694-1709, 2007. 
[2] ASHBEE, K.H., Fundamental, principles of fiber reinforced composites, 2nd ed., Lancaster, Technomic Publ. Company, 1993.

[3] MALLICK, P.K., Fiber-reinforced composites, materials manufacturing and design, 2nd ed., Marcel Dekker Publ, New York,., 1993.

[4] CHAWLA, K.K., Composite materials science and engineering, 2nd ed., Spring-Verlag, New York, , 1998.

[5] BLEDZKI, A.K., GASSAN, J., "Composites reinforced with cellulose-based fibers", Progress in Polymer Science, v. 24, n. 2, pp. 221-274, 1999.

[6] NABI-SAHED, D., JOG, .J.P., "Natural fiber polymer composites: a review", Advances in Polymer Technology, v. 18, n. 4, pp. 221-274, 1999.

[7] MOHANTY, A.K., MISRA, M., DRZAL, L.T., "Sustainable biocomposites from renewable resources: opportunities and challenges in the green material world", Journal of Polymer Environment, v. 10, n.1-2, pp. 9-26, 2002.

[8] CROCKER, J., "Natural materials innovative natural composites", Materials Technology, v. 2-3, pp.174-178, 2008.

[9] MONTEIRO, S.N., LOPES, F.P.D., FERREIRA, A.S., et al., "Natural fiber polymer matrix composites: cheaper, tougher and environmentally friendly", JOM, v. 61, pp. 17-22, 2009.

[10] ZAH, R., HISCHIER, R., LEÃO, A.L. et al., "Curaua fibers in automobile industry - A sustainability assessment”, Journal of Cleaner Production, v. 15, n.11-12, pp. 1032-1040, 2007.

[11] MONTEIRO, S.N., SATYANARAYANA, K.G., LOPES, F.P.D., "High strength natural fibers for improved polymer matrix composites”, Materials Science Forum, v. 638-642, pp. 961-966, 2010.

[12] CLEGG, D.W., COLLYER, A.A., Irradiation effects on polymers, London, Elsevier Science Publishers, 1991.

[13] CHOI, H.Y., HAN, S.O., LEE, J.S., "Surface morphological, mechanical and thermal characterization of electron beam irradiated fibers", Applied Surface Science. v. 255, pp. 2466-2473, 2008.

[14] TAKINAMI, P.Y.I., SHIMAZAKI, K., COLOMBO, M.A., et al., "Gelatin/piassava composites treated by electron beam radiation”, Revista Matéria, v. 15, n. 2, pp. 339-344, 2010.

[15] BUCHALLA, R., SCHÜTTLER, C., BÖGL, K.W., "Effect of ionizing radiation on plastic food packaging materials: a review, Part 1. Chemical and Physical Changes", Journal of Food Protection, v. 56, n. 11, pp. 991-997, 1993.

[16] MACHI, S., "New trends of radiation processing applications", Radiation Physics and Chemistry, v. 47, n. 3, pp. 333-336, 1996.

[17] DORSCHNER, H., LAPPAN, U., LUNKWITZ, K., "Electron beam facility in polymer research: radiation induced functionalization of polytetrafluoroethylene", Nuclear Instruments and Methods in Physics Research B, v. 139, pp. 495-501, 1998.

[18] KHAN, F., AHMAD, S.R., KRONFLI, E., "Stability of jute fibers on exposure to ionizing radiation", Polymer Degradation and Stability, v. 63, pp. 79-84, 1999.

[19] ROUIF, S., "Radiation cross-linked polymers: Recent developments and new applications", Nuclear Instruments and Methods in Physics Research B, v. 236, pp. 68-72, 2005.

[20] RATNAM, C.T., RAJU, G., YUNUS, W.Z.W., "Oil palm empty fruit bunch (OPEFB) fiber reinforced PVC/ENR blend-electron beam irradiation”, Nuclear Instruments and Methods in Physics Research B. v. 265, pp. 510-514, 2007.

[21] SANTOS, N.S.S., DIAS, C.G.B.T., SANCHES, E.M.S., et al., "Microstuctural and mechanical characterization of miriti fiber for utilization as reinforcement on polymeric composites" (in Portuguese), In: 
Proceedings of the Brazilian Congress on Materials Science and Engineering - 18 CBECIMAT, pp. 35653573, Porto de Galinhas, PE, Brazil, November 2008.

[22] PORTELA, T.G.R., COSTA, L.L., LOPES F.P.D., et al., "Characterization of fibers from different parts of the buriti palm tree", In: Proceedings of the TMS - Conference, Characterization of Minerals Metals \& Materials Symposium, pp. 1-7, Seattle, USA, March 2010.

[23] PORTELA, T.G.R., COSTA, L.L., SANTOS, N.S.S., et al., "Tensile behavior of lignocellulosic fiber reinforced polymer composites: Part II buriti petiole/polyester", Revista Matéria, v. 15, n. 2, pp. 216-222, 2010. 